\title{
A UTILIZAÇÃO DAS TICS COMO RECURSO PEDAGÓGICO INOVADOR NO CURSO DE AUXILIAR DE SAÚDE BUCAL
}

\section{ARTIGO ORIGINAL}

CREMONESE, Miriam Regina de Araujo ${ }^{1}$

COSTA, Maria Salete da ${ }^{2}$

CREMONESE, Miriam Regina de Araújo. COSTA, Maria Salete da. A utilização das TICs como recurso pedagógico inovador no curso de auxiliar de saúde bucal. Revista Científica Multidisciplinar Núcleo do Conhecimento. Ano 04, Ed. 10, Vol. 12, pp. 56-79. Outubro de 2019. ISSN: 2448-0959, Link de acesso: https://www.nucleodoconhecimento.com.br/educacao/auxiliar-de-saude$\underline{\text { bucal }}$

\section{RESUMO}

O presente trabalho tem por objetivo propor um plano docente para a disciplina de Materiais Dentários do curso de Auxiliar de Saúde Bucal, utilizando as tecnologias de informação e comunicação, de forma a tornar as aulas mais atrativas e estimulantes às alunas e fortalecer a relação professora/alunas, indagando os métodos tradicionais de ensino, por vezes cansativos e entediantes. O estudo apresenta uma pesquisa explorativa de caráter qualitativo, baseado numa revisão bibliográfica, com método indutivo e dialético. Discutimos sobre a importância da tecnologia digital para a formação do aluno e propomos formas diversificadas de aplicação dos recursos tecnológicos em sala de aula. O resultado do trabalho é uma nova proposta pedagógica para a disciplina citada, com estratégias de ensino e avaliação inovadoras, intensificando a aprendizagem, tornando o ambiente escolar mais

${ }^{1}$ Pós graduada em Docência no Ensino Técnico, Especialista em Odontologia em Saúde Coletiva, Bacharel em Odontologia, Licenciada em Letras, Cirurgiã-dentista.

${ }^{2}$ Mestrado em Educação, Graduação em Filosofia. 
interessante, aumentando a confiança e o respeito mútuo entre alunas e professora bem como refinando habilidades e competências exigidas dos alunos frente ao atual mercado de trabalho.

Palavras-chave: Plano docente, auxiliar de saúde bucal, materiais dentários, tecnologias de informação e comunicação.

\section{INTRODUÇÃO}

O estudo trata da utilização das TICs na formação de auxiliares de saúde bucal, como recurso inovador e estimulante ao aprendizado, relacionando o cotidiano e a realidade situacional das alunas com a vivência em sala de aula. Este tema, estudado no curso de Pós Graduação de Docência no Ensino Técnico, entre 2017 e 2018 em Instituição de ensino privada, vem facilitar o desenvolvimento do conteúdo da disciplina de Materiais Dentários do curso de Auxiliares de Saúde Bucal, que exige atenção e memorização do aluno.

Falaremos sobre a importância da utilização das TICs como recurso pedagógico inovador no ensino técnico, especialmente no curso de Auxiliar de Saúde Bucal, e especificamente na disciplina de Materiais Dentários. $O$ assunto a ser tratado é como e com quais recursos tecnológicos poderemos difundir a utilização das TICs na disciplina de Materiais Dentários, com o objetivo de desenvolver a disciplina de forma atrativa e competente.

Para tanto, nos propomos a discutir sobre a importância da tecnologia digital para a formação do aluno; a sugerir formas diversificadas de aplicação dos recursos tecnológicos em sala de aula e a elaborar um plano docente definindo estratégias que oportunizem aulas mais dinâmicas e agradáveis para as alunas, garantindo a aprendizagem com melhor desempenho e propiciando o fortalecimento da relação professora e alunas.

O estudo apresenta uma pesquisa explorativa de caráter qualitativo, baseado numa revisão bibliográfica, com método indutivo e dialético. A delimitação do tema focou na 
utilização das TICs no ensino técnico, que culminará na elaboração de um plano docente para a disciplina citada. O pretenso estudo justifica-se pela necessidade de extrapolarmos os métodos tradicionais de ensino, por vezes cansativos e entediantes. A utilização das tecnologias digitais já são amplamente usadas pelas alunas devido à faixa etária. $O$ desenvolvimento de estratégias nesse sentido intensificará a aprendizagem, tornando o ambiente escolar mais interessante, aumentando a confiança e o respeito mútuo entre alunas e professora, refinando habilidades e competências exigidas dos alunos frente ao atual mercado de trabalho.

A escola representa na sociedade moderna o espaço de formação não apenas das gerações jovens, mas de todas as pessoas. Em um momento caracterizado por mudanças velozes, as pessoas procuram na educação escolar a garantia de formação que Ihes possibilite o domínio de conhecimentos e melhor qualidade de vida. (KENSKY, 2007, p.19)

Assim, apresentamos uma introdução delimitando nosso tema, especificando objetivos, justificando o estudo e levantando algumas hipóteses. Em seguida apresentaremos o seguimento do trabalho em dois capítulos, o primeiro faz uma revisão bibliográfica sobre a utilização das TICs na vida do ser humano e seu reflexo na educação, enquanto que o segundo capítulo propõe um plano de trabalho docente utilizando as TICs como estratégia inovadora no desenvolvimento de uma disciplina que, invariavelmente, é realizado de uma forma tradicional.

Dessa forma, estaremos introduzindo na escola esses recursos tecnológicos que são já utilizados comumente em espaços familiares e sociais e apreciados pelas alunas;

“...proporcionando uma nova maneira de se tratar não só com a tecnologia no dia a dia da escola e a relação professor aluno, como também mudar a maneira com que os alunos e professores tratam (e produzem) o conhecimento." (SALDANHA, 2009, p. 138) 


\section{DESENVOLVIMENTO}

\subsection{AS TECNOLOGIAS DE COMUNICAÇÃO}

\subsubsection{O PAPEL DA TECNOLOGIA NA SOCIEDADE HUMANA}

Segundo Kensky (2007), desde a criação da humanidade já houve o domínio da tecnologia, que os homens utilizavam como instrumento de poder sobre seus semelhantes, como garantia de sobrevivência.

Com a evolução dos tempos, as novas tecnologias que surgiram não só garantiram a defesa, mas também a dominação sobre outros povos. E o surgimento de uma nova tecnologia levava a outras, para outros fins, e assim sucessivamente. A sociedade passou a se adaptar a elas, e estas, a fazer parte do cotidiano, interferindo no comportamento humano e definindo culturas dos grupos sociais em cada época da história.

Atualmente, nossa vida é marcada pelas novas tecnologias digitais de comunicação e pela microeletrônica. Sua utilização modifica e determina o modo de vida social e profissional das pessoas. Cada forma que utilizamos dessa tecnologia, chamamos técnica. Caracterizam-se por estarem em constante transformação. Seu campo de ação é virtual e seu foco é a informação. Isso possibilitou o surgimento de novas profissões, específicas para essa realidade.

\subsubsection{AS NOVAS TECNOLOGIAS E A COMUNICAÇÃO HUMANA}

Para Kensky (2007), essa nova cultura acaba por excluir indivíduos que não a dominam. São ferramentas que possibilitam a ampliação da memória e da comunicação, especialmente em educação formal. A linguagem digital modificou a narrativa, antes linear e monótona. Agora, oferece uma linguagem descontínua, intercalando novos conteúdos, espaços, tempos e pessoas, na forma do hipertexto e hipermídias. A facilidade da navegação simplifica e torna o fenômeno mais interessante ao usuário. Isso veio modificar completamente nossa realidade. Houve 
uma confluência de mídias, que são utilizadas para inúmeros fins e em tempo real, dos mais variados lugares.

A utilização das mídias digitais permeia os ambientes sociais, entretenimento, comerciais, escolares, científicos, religiosos e são compartilhados em grupos. A internet é ponto da junção e de transmissão dos mais variados objetivos.

Surgem novos termos para definição dessa cultura: o ciberespaço, onde tudo acontece e é compartilhado por todos, e a cibercultura, resultado dessa vivência.

Com esse novo suporte de informação e de comunicação emergem gêneros de conhecimentos inusitados, critérios de avaliação inéditos para orientar o saber, novos atores na produção e tratamento dos conhecimentos. Qualquer política de educação terá que levar isso em conta. (LÉVY, 1999, p. 169).

Nesse novo modelo de sociedade, modifica-se também a relação das pessoas com o conhecimento e com o poder, que estarão disponíveis a qualquer um, a qualquer hora e em qualquer lugar. Surge a necessidade de constante atualização e de aquisição de outras habilidades, como aprender outro idioma, especialmente o inglês. A possibilidade de interatividade da televisão é outra característica.

As tecnologias de informação e comunicação não são simples recursos tecnológicos, elas têm suas características próprias, baseadas numa nova cultura, a cultura digital. $\mathrm{E}$ isso reflete no comportamento social.

Assim, uma linguagem nova vem surgindo, possibilitando a comunicação entre povos que falam idiomas diferentes. Seria uma linguagem que une a linguagem digital, o inglês vulgar e a linguagem icônica dos emoticons.

\subsubsection{A TECNOLOGIA NA EDUCAÇÃO}

Kensky (2007) afirma que essas mudanças na cultura social chegam até a escola e na forma de fazer educação, uma vez que os grupos trazem junto a experiência cotidiana. É necessário conhecê-la melhor e transformá-la em aliada dentro de nossas possibilidades, e não apenas dominar sua técnica. 
Sabemos que a maioria das tecnologias são utilizadas como uma auxiliar da aprendizagem. Elas participam de muitas ações na escola, principalmente as burocráticas, mas ainda não foram exploradas em todas suas possibilidades pedagógicas. Dentre elas, podemos citar a flexibilidade de horários, métodos de ensino, flexibilidade no espaço físico, interatividade disciplinar, aproveitamento da hipermídia, utilização de softwares e programas, metodologias ativas, entre outros, exigindo atualização constante de conhecimentos e competências, que podem ser adquiridas com o próprio discente e propiciando a formação de profissionais e cidadãos autônomos, críticos e criativos.

Milhões de pessoas conectadas, usufruindo das informações disponíveis em rede, poderão construir juntas muitos projetos colaborativos, que servirão aos interessados. Esse tipo de trabalho tende a crescer e a possibilitar o acesso a milhões de outros, que também poderão usufruir ou colaborar com ele. Isso rompe com hierarquias e modifica a forma de construção do conhecimento. É uma nova exigência para a escola formal, a readaptação do quadro educacional e global.

A atitude dos jovens que fazem parte dessa geração digital não é passiva. Para eles, o importante é participar e executar várias ações ao mesmo tempo, fazer o máximo em um mínimo de tempo, aprendem e constroem sozinhos, isto é, o aluno é o protagonista de seu conhecimento.

Apesar dos avanços e vantagens das novas tecnologias, há dificuldades pela frente, individuais e coletivas, como problemas técnicos, econômicos, interesse do aluno, preparo do professor, a não adequação da tecnologia ao conteúdo, ausência de formação continuada, ausência do hábito e motivação dos professores por motivo de questões profissionais, realidade diversificada entre escolas, etc.

\subsubsection{O NOVO MODELO DE ESCOLA}

De acordo com Kensky (2007), a escola tradicionalmente preparava os indivíduos para a vida social, o trabalho e para as descobertas científicas. Numa sociedade que prioriza a informação as pessoas necessitam ter um preparo básico para apreendê-la 
e se manterem atualizados para utilizá-la. Nessa sociedade de incessantes transformações, a escola precisa ser formadora de cidadãos capazes de constante adaptação na convivência social e profissional, diante dos desafios impostos em sua realidade, desenvolvendo habilidades, atitudes e valores necessários para tal.

O novo modelo de escola deverá utilizar as novas tecnologias para integrar escola e comunidade, unindo o formal e o informal, iniciando por ouvir seus alunos e adaptar novas abordagens pedagógicas que as mídias digitais viabilizam. Não haverá limites físicos, já que o ambiente virtual permite a convivência em qualquer momento ou espaço.

A geração jovem, nativa digital, vem para a escola com habilidades específicas desenvolvidas por meio dos jogos que compartilham na internet. Essas habilidades serão importantes no comportamento profissional, tais como, raciocínio, espírito de equipe, desenvolvimento de estratégias, ambição coletiva, definição de papéis, entrosamento, respeito ao parceiro, comunicação, regras de bom comportamento em rede, fluência digital, habilidade de escrita e desenho com ambas as mãos e aguçamento sensorial.

Os ambientes virtuais estão se expandindo dos computadores para os celulares, facilitando a portabilidade e o uso desse tipo de mídia, que hoje converge várias funções em um só aparelho. O desafio é o de utilizarmos de uma forma pedagógica no processo ensino-aprendizagem.

Nesse novo perfil, o discente deverá adquirir autonomia, interagir socialmente em novas comunidades, preparando para o exercício da cidadania e espírito crítico, para ser sujeito de sua própria história, recriando um novo significado para a educação com alunos motivados e inspirados para aprender. É uma nova educação voltada para a aprendizagem colaborativa e cooperativa, unindo várias mentes separadas por vários fatores e facilitando a quem apresenta dificuldades ao ensino presencial pelos mais variados motivos.

O uso criativo das tecnologias pode auxiliar os professores a transformar o isolamento, a indiferença e a alienação com que costumeiramente os 
alunos frequentam as salas de aula, em interesse e colaboração, por meio dos quais eles aprendam a aprender, a respeitar, a aceitar, a serem pessoas melhores e cidadãos participativos. Professor e aluno formam "equipes de trabalho" e passam a ser parceiros de um mesmo processo de construção e aprofundamento do conhecimento: aproveitar o interesse natural dos jovens estudantes pelas tecnologias e utilizá-las para transformar a sala de aula em espaço de aprendizagem ativa e reflexão coletiva; capacitar os alunos não apenas para lidar com as novas exigências do mundo do trabalho, mas, principalmente para a produção e manipulação das informações e para o posicionamento crítico diante dessa nova realidade. (KENSKY, 2007, p.103)

Para o sucesso desse trabalho será necessário cuidadoso planejamento. A transição poderá ocorrer com o uso de material online complementado por aulas presenciais com menor número de alunos, uso das mídias digitais variadas, fóruns de discussão, monitoria online, laboratórios virtuais, projetos colaborativos entre outros processos pedagógicos. Isso possibilita uma interação dinâmica e atraente no ciberespaço, para os alunos e professores envolvidos.

Essa possibilidade de aprendizagem virtual permite a interação síncrona e assíncrona permanente de seus usuários, sociabiliza e estimula a cooperação, favorece o acesso rápido à informação e comunicação, a facilidade de navegação na internet, o acesso em dia e horários diversificados, e, mesmo assim, poderão sentir que estão trabalhando conjuntamente.

A educação tem outro grande aliado, os blogs, espécie de diário, que trata de diversos assuntos e que devem ser constantemente atualizados. São simples de usar e possibilitam um trabalho coletivo, transformando-o em trabalho pedagógico escolar. Assim também poderemos tratar programas e aplicativos que possam ser utilizados em rede a contribuírem para a construção da aprendizagem colaborativa.

\subsubsection{AS DIFICULDADES ENCONTRADAS}

Kensky (2007) reitera que, como toda mudança, há alguns inconvenientes, como o acesso aos equipamentos fora da escola, inviabilidade econômica para aquisição do computador, uso de softwares facilmente ultrapassados, currículo fragmentado, carga 
horária, formação deficiente dos professores para uso pedagógico das TICs, manutenção técnica e qualidade da internet.

As transformações ocorrerão de forma gradual e serão enormes, mas não excluirão 0 papel principal da escola em relação à educação. Necessária será a reformulação dos programas pedagógicos, a flexibilização das estruturas de ensino, a interdisciplinaridade dos conteúdos, o relacionamento da escola com a comunidade, a flexibilização de horários, a mudança dos currículos, a administração hierarquizada e cíclica, a autonomia da escola na realização de seus próprios projetos educacionais com instituições nacionais e internacionais, mudança no relacionamento professor/aluno dentro e fora da escola, estabelecimentos de ensino com aprendizagem permanente, reorganização das políticas educacionais e da avaliação, uso da criatividade, remuneração profissional adequada, tempo para auto formação e formação continuada, etc.

A escola da aprendizagem é muito diferente da escola do ensino. A escola da aprendizagem precisa de novos espaços, de outros tipos de temporalidades, de outra organização dos grupos de alunos e professores, de outras propostas pedagógicas, essencialmente novas e que se adaptem a diferentes formas e estilos de aprender de todos os participantes: professores e alunos. (KENSKY, 2007, p. 109).

O mais importante é que as pessoas estejam reunidas preocupadas em aprender juntas, isso dará base para um novo modelo de educação através do engajamento destas, de uma forma séria e responsável.

Há docentes que resistem às mudanças; estes, criarão um abismo entre si e seus alunos, uma vez que o estilo de vida dos discentes interfere de maneira direta na escola, já que estes convivem com a tecnologia no cotidiano, de uma forma natural. E assim, ela ganha espaços em outros territórios, sociais e profissionais. Há de haver uma atualização e acompanhamento dessa nova forma de viver para conviver em sociedade de uma forma geral.

Para garantir que esse processo avance, precisamos de equipes técnicas bem treinadas para o desenvolvimento e manutenção dos equipamentos e para apoio e 
treinamento da equipe pedagógica e administrativa. Uma nova forma de ver e pensar educação.

Grande reformulação curricular deve ser implementada. Criam-se disciplinas e atividades. Viabilizam-se projetos interdisciplinares e interinstitucionais. Formam-se equipes mistas: professores, técnicos e alunos integrados em projetos e atividades. Períodos letivos diferenciados e oferta de ensino a distância encaminham as escolas para o funcionamento permanente, o ano inteiro. [...] Um tempo maior para o planejamento das atividades. Estabelecimento de intercâmbio diversos e realização de cursos permanentes de aperfeiçoamento e atualização de todo staff pessoal e administrativo. (KENSKY, 2007, p.126).

\subsection{A OPINIÃO DE OUTROS AUTORES}

Lendo outros autores, observamos a concordância de ideias no sentido de buscarmos uma solução para as mudanças que já ocorrem na educação e para as que ainda estão por vir, permeando outras questões existentes.

Pretto (2013), disserta sobre nossa atual crise na educação e sobre a necessidade de aproximação dessa nova realidade virtual do novo milênio ao sistema de ensino, a despeito da rapidez do surgimento dessas mudanças. Não podemos negar ou ignorar esse contexto, mas sim, desenvolver novas políticas educacionais que possibilitem a formação de um novo ser humano. Esse é mais um desafio a ser solucionado no Brasil, o "analfabetismo" digital, antes mesmo de termos solucionado o analfabetismo e letramento da população desfavorecida, forçosamente influenciado pela economia internacional e velocidade do desenvolvimento científico e tecnológico.

O autor comenta que há ainda um grande preconceito dos educadores em relação a essas mídias e uma grande dificuldade de entendimento desses jovens, se constituindo em um fenômeno mundial e na formação destes profissionais.

Para a passagem do velho modelo de escola para uma nova escola, com futuro, torna-se necessário observar atentamente alguns aspectos da atual estrutura educacional. Um desses aspectos, certamente, é promover uma revisão urgente na formação dos professores e no papel das universidades públicas nessa área. (PRETTO, 2013, p.140). 
Silva; Silva (2014), constatam que as mídias portáteis fazem parte cada dia mais do cotidiano dos estudantes, de forma disseminada, provocando mudanças no cotidiano escolar também. Isso traz à tona a discussão sobre a crença de utilização destas mídias apenas como atrativo, possibilidade de inclusão digital e inovação curricular. Os autores afirmam que estes argumentos reduzem a questão à simples utilização dos aparelhos, sem uma democratização de seu uso e sem a possibilidade de espaços sociais conectados. A aprendizagem não necessita estar limitada a um espaço físico, mas ser democratizada para acesso de todos, para interação entre usuários que o façam sob um olhar crítico, fortalecido pela reestruturação pedagógica e curricular, voltada à autonomia do educando. Mas deixam clara a necessidade de preparo da equipe, instituição, professor, possibilitando sua autoria e seu empoderamento no processo ensino-aprendizagem.

Para Saldanha (2009), a decisão do momento e forma do uso das mídias portáteis cabem ao professor e aos alunos e em atividades diferentes aplicadas pedagogicamente. Mas, o mais importante é a flexibilização do currículo, de forma que essas inovações elevem a qualidade do ensino verdadeiramente.

Este autor identifica em seu estudo que, além da preparação dos professores para apropriação da tecnologia, seu uso adequado e da alteração do currículo, foi necessária uma melhoria na estrutura física da escola para a utilização das TICs em sala de aula, como o aumento dos pontos de acesso das redes sem fio, instalação de projetores multimídia nas salas, lousa interativa, disponibilização de pendrives, mobiliário adequado e redimensionamento da rede de energia que dá suporte à estrutura. Isso dependerá da realidade de cada escola. $O$ trabalho contou também com o apoio de técnicos de informática e pedagogos.

Os pedagogos envolvidos no estudo apontaram questões a serem desenvolvidas e avaliadas nos alunos e professores, como autonomia, domínio da tecnologia, motivação para aprendizagem em qualquer hora e local, capacidade para trabalhar em equipe, formação continuada dos professores, auxílio de monitores em aula, avaliação contínua do aluno e do professor, autogestão de conhecimento do aluno, 
permeado pela colaboração entre todos. Entretanto, ainda há muita pesquisa a ser feita para consolidarmos a mudança do paradigma tradicional na educação.

"Mudou a estrutura econômica, mudou o cotidiano de nossas vidas e a escola precisa acompanhar essas mudanças e trabalhar com os instrumentos culturais e as linguagens que fazem parte da vida dos alunos da nova geração". (SALDANHA, 2009, p. 90).

De acordo com as conclusões de Setton (2010, p. 107):

As discussões relativas às interfaces entre educação e mídias estão ainda em fase de consolidação. Ainda que um grupo de estudiosos venha se debruçando sobre esse tema, falta um corpo de pesquisas teóricas e empíricas com viabilidade acadêmica nacional.

Conforme Oliveira (2016) o governo brasileiro já vem desenvolvendo políticas públicas para possibilitar a introdução das tecnologias digitais no país e tentar minimizar os impasses existentes nesta área. Apesar disso, a sua utilização como recurso pedagógico ainda é pequena no que tange à educação.

De acordo com o novo papel do professor mediador, cabe aqui uma revisão da prática pedagógica do professor, capacitando-o para o desempenho de suas funções, estabelecimento de parcerias com outras realidades, exercício da sua autonomia com a escola e comunidade, integração destas práticas ao currículo escolar, vinculadas à realidade social de cada região ou comunidade e principalmente ao perfil de seus alunos.

"O tempo é fundamental para que o professor aprenda a usar as tecnologias, reflita sobre as possibilidades de usos pedagógicos e compartilhe suas impressões com seus pares." (OLIVEIRA, 2016, p. 47).

Finalizando, isso tudo facilitará a atuação do professor que se interessar realmente em mudar o tradicional paradigma educacional no Brasil e no mundo. Há que haver interesse e criatividade. 


\section{PLANO DE TRABALHO DOCENTE}

\subsection{DESCRIÇÃO DO PLANO DE TRABALHO DOCENTE}

INSTITUIÇÃO: Instituição de ensino privada.

CURSO: Auxiliar de Saúde Bucal (ASB), regulamentado pelo MEC, lei 11.889 de 24 de dezembro de 2008, que trata do exercício das profissões de Técnico em Saúde Bucal e Auxiliar de Saúde Bucal.

CARGA HORÁRIA DO CURSO: $400 \mathrm{~h}$, sendo 168 aulas teóricas, 50 aulas práticas, 82 horas de atividades extras e $100 \mathrm{~h}$ de estágio supervisionado.

DISCIPLINA: Materiais Dentários

CARGA HORÁRIA DA DISCIPLINA: 24 horas, distribuídas em 3 horas aulas corridas semanais, durante 8 semanas.

SEMESTRE: III semestre

PROFESSOR RESPONSÁVEL: Miriam Regina de Araujo Cremonese

EMENTA: Plano de trabalho docente relativo ao desenvolvimento da disciplina de Materiais Dentários, com estratégias e avaliação inovadoras, introduzindo tecnologias de informação e comunicação no processo ensino-aprendizagem.

OBJETIVOS: Reconhecer e manipular adequadamente os materiais de uso odontológico em suas diferentes especialidades, utilizando as tecnologias de informação e comunicação como recurso pedagógico inovador, tornando as aulas mais atrativas para o grupo discente e fortalecendo a relação professora/alunas.

"O planejamento é um processo que exige organização, sistematização, previsão, decisão e outros aspectos na pretensão de garantir a eficiência e eficácia de uma ação, [...]" (LEAL, 1999). 
O planejamento de ensino requer reflexão sobre a conduta e escolhas do professor e se relaciona com os objetivos, conteúdos, estratégias e a avaliação do processo ensino-aprendizagem, exigindo do professor uma prática reflexiva antes, durante e depois deste processo, que deverá ser contínuo e dinâmico. A reflexão culmina em um planejamento e esse planejamento resulta em um plano, que concretiza as ações planejadas. No caso deste trabalho, será proposto um plano de trabalho docente.

Como todo planejamento é intencional e relata as várias etapas elencadas para que este venha a ser bem-sucedido, faz-se necessário termos em mente o perfil do aluno, da escola e da comunidade em que estão inseridos.

Por motivo dessa realidade, apresentamos uma proposta de inovação para as aulas da disciplina já citada, de forma a torná-las mais interessantes e facilitar o aprendizado, atentando para objetivos coerentes com as necessidades encontradas, conteúdos e competências necessários, estratégias inovadoras em metodologias ativas e avaliação em processo, englobando os três tipos, diagnóstica, formativa e somativa.

A partir de uma avaliação diagnóstica, levantaremos as necessidades a serem superadas. De posse do projeto de ensino oficial, o professor criará seu plano de trabalho docente, contemplando o alcance dos objetivos e a superação das dificuldades.

De acordo com o quadro de trabalho docente abaixo transcrito, observamos que foi elaborado para a disciplina de materiais dentários, do curso de Auxiliar de Saúde Bucal e apresenta os objetivos que necessitam ser atendidos, relacionados a conhecimentos específicos, desenvolvimento de habilidades manuais, memorização, posicionamento, desenvoltura, criatividade, responsabilidade, iniciativa, autonomia, trabalho em equipe, aumento do interesse e participação em aula, melhoria no relacionamento entre professora e alunas e o exercício da cidadania. Os objetivos são elaborados para que a ocorrência da aprendizagem seja visível e avaliável e estes definem o que se planeja alcançar. Dessa forma, o professor deve saber como 
estabelecerá suas estratégias de ensino para o sucesso dos objetivos traçados e de que forma fará a avaliação para ter essa certificação.

Os conteúdos são de extrema relevância na formação teórica e prática da profissão das alunas, mas seu estudo e aplicabilidade poderá se tornar mais acessível e interessante, dependendo da forma com que forem desenvolvidos, com introdução de outros valores relativos ao caráter, à ética, à sociabilização, etc.

Para tanto, elegemos estratégias inovadoras e criativas, utilizando as tecnologias de informação e comunicação, e propiciando aquisição das competências acima citadas. Esperamos desta forma melhorar todo o processo de ensino-aprendizagem referente à disciplina. O uso de metodologias ativas em educação favorece a prática pedagógica formativa, o caráter reflexivo do professor e a aprendizagem significativa, sabendo-se que poderemos tomar caminhos diferentes no processo pedagógico e respeitando os diferentes estilos de aprendizagem dos alunos. Os recursos utilizados levarão em conta a realidade da instituição e estarão coerentes com o conteúdo e estratégias propostas. Abriremos espaço para sugestões das alunas durante esse período.

A avaliação do trabalho iniciará com uma avaliação diagnóstica, levantando a situação inicial em relação ao perfil das alunas, aos conhecimentos prévios e à realidade da escola. No decorrer do trabalho, nos basearemos na avaliação formativa, que permite ao professor acompanhar o desenvolvimento da aprendizagem, corrigindo falhas, dificuldades e até mudar a orientação do trabalho, obedecendo o quadro de rubricas que propõe critérios avaliativos desdobrados em níveis de desempenho. Para finalizar, cada módulo apresentará uma avaliação somativa, sendo que anteriormente os conteúdos serão retomados, realizadas novas questões do tipo que serão empregadas na avaliação somativa e sanadas as dúvidas que ainda existirem. Após a realização da prova, a correção será feita em sala de aula, com as alunas, discutindo certo e errado como meio de fixação do conteúdo.

As TICs fazem também a ligação do aluno/escola com a sociedade, possibilitando divulgação e atualização dos resultados e o compartilhamento do conhecimento. 


\subsection{QUADRO PLANO DE TRABALHO DOCENTE}

\begin{tabular}{|c|c|c|c|c|c|}
\hline $\begin{array}{l}\text { UNIDAD } \\
\text { E }\end{array}$ & $\begin{array}{l}\text { OBJETIVOS / } \\
\text { COMPETÊNCI- } \\
\text { AS }\end{array}$ & $\begin{array}{l}\text { CONTEÚ- } \\
\text { DOS }\end{array}$ & $\begin{array}{l}\text { ESTRATÉGI- } \\
\text { AS }\end{array}$ & $\begin{array}{l}\text { AVALIA- } \\
\text { ÇÃO }\end{array}$ & $\begin{array}{l}\text { REFERÊNCIAS } \\
\text { BIBLIOGRÁFICA } \\
\text { S }\end{array}$ \\
\hline $\begin{array}{l}\text { I- } \\
\text { Materiais } \\
\text { de } \\
\text { Dentística } \\
\text {, Cirurgia, } \\
\text { Periodont } \\
\text { ia e } \\
\text { Prevençã } \\
\text { o à cárie } \\
\text { dental }\end{array}$ & $\begin{array}{l}\text { *Identificar, } \\
\text { debater e } \\
\text { manipular } \\
\text { adequadamente } \\
\text { o uso dos } \\
\text { materiais } \\
\text { dentários das } \\
\text { especialidades } \\
\text { de dentística, } \\
\text { cirurgia, } \\
\text { periodontia e } \\
\text { prevenção à } \\
\text { cárie dental; } \\
\text { "Proporcionar } \\
\text { meios para a } \\
\text { interação do } \\
\text { conteúdo com } \\
\text { tecnologias de } \\
\text { informação e } \\
\text { comunicação; } \\
\text { *Elaborar } \\
\text { materiais digitais } \\
\text { que registrem as } \\
\text { atividades } \\
\text { realizadas } \\
\text { durante a } \\
\text { pesquisa, } \\
\text { aplicação e } \\
\text { resultados do } \\
\text { estudo dos } \\
\text { materiais } \\
\text { abordados; } \\
\text { Desenvolver } \\
\text { competências } \\
\text { relativas a } \\
\text { habilidades e } \\
\text { memorização, } \\
\text { responsabilidade } \\
\text { e autonomia; }\end{array}$ & $\begin{array}{l}\text { Característi- } \\
\text { cas, } \\
\text { proprieda- } \\
\text { des, } \\
\text { indicação e } \\
\text { manipulação } \\
\text { de materiais } \\
\text { dentários } \\
\text { utilizados } \\
\text { para } \\
\text { dentística e } \\
\text { prevenção de } \\
\text { doenças } \\
\text { bucais, tais } \\
\text { como verniz } \\
\text { cavitário, } \\
\text { resina } \\
\text { composta e } \\
\text { adesivos, } \\
\text { amálgama, } \\
\text { cimento de } \\
\text { ionômero de } \\
\text { vidro tipo Il e } \\
\text { III, cimento } \\
\text { de hidróxido } \\
\text { de cálcio, } \\
\text { cimento de } \\
\text { óxido de } \\
\text { zinco } \\
\text { eugenol, fita } \\
\text { matriz da } \\
\text { aço, fita } \\
\text { poliéster, tira } \\
\text { de lixa de } \\
\text { acabamento, } \\
\text { lençol de } \\
\text { borracha, } \\
\text { selantes, } \\
\text { algodão, } \\
\text { papel toalha, }\end{array}$ & $\begin{array}{l}\text { Inicialmente, a } \\
\text { turma de } \\
\text { dezesseis } \\
\text { alunas será } \\
\text { dividida em } \\
\text { quatro grupos } \\
\text { com formação } \\
\text { de quatro } \\
\text { alunas cada. } \\
\\
\text { Cada grupo fará } \\
\text { uma visita a um } \\
\text { local ideal para } \\
\text { a realização de } \\
\text { uma entrevista. } \\
\text { (Que poderá ser } \\
\text { consultório, } \\
\text { laboratório de } \\
\text { prótese ou setor } \\
\text { comercial). Será } \\
\text { agendada uma } \\
\text { entrevista (Por } \\
\text { elas) e realizada } \\
\text { a gravação de } \\
\text { um vídeo com } \\
\text { smartphone, } \\
\text { com o } \\
\text { profissional } \\
\text { local } \\
\text { responsável e } \\
\text { com os } \\
\text { materiais } \\
\text { utilizados nesse } \\
\text { ambiente. A } \\
\text { princípio de } \\
\text { uma maneira } \\
\text { informal. O } \\
\text { vídeo será } \\
\text { apresentado em } \\
\text { sala de aula } \\
\text { para os outros }\end{array}$ & $\begin{array}{l}\text { A avaliação } \\
\text { será } \\
\text { baseada } \\
\text { numa } \\
\text { avaliação } \\
\text { diagnóstica } \\
\text { para } \\
\text { levantar os } \\
\text { conheci- } \\
\text { mentos } \\
\text { prévios e } \\
\text { perfil dos } \\
\text { alunos; } \\
\\
\text { *Na } \\
\text { avaliação } \\
\text { formativa, } \\
\text { obedecendo } \\
\text { os critérios } \\
\text { de uma } \\
\text { rubrica que } \\
\text { serão } \\
\text { observados } \\
\text { durante o } \\
\text { decorrer da } \\
\text { disciplina (a } \\
\text { rubrica com } \\
\text { os critérios } \\
\text { de } \\
\text { avaliação e } \\
\text { níveis de } \\
\text { desdobra- } \\
\text { mento vem } \\
\text { na sequên- } \\
\text { cia do } \\
\text { quadro do } \\
\text { plano de } \\
\text { trabalho } \\
\text { docente) e } \\
\text { em } \\
\end{array}$ & $\begin{array}{l}\text { ANUSAVICE, K. J. } \\
\text { \& PHILLIPS. } \\
\text { Materiais } \\
\text { Dentários. } \\
11^{\text {a }} \text { ed. Rio de } \\
\text { Janeiro: Elsevier } \\
\text { LTDA, 2005. } \\
\text { BORGES, Lusiane } \\
\text { Camilo. ASB\& TSB } \\
\text { - Formação e } \\
\text { Prática da Equipe } \\
\text { Auxiliar. Rio de } \\
\text { Janeiro: Elsevier, } \\
\text { 2015. } \\
\text { FERRAZ, Ana } \\
\text { Paula do Carmo; } \\
\text { BELHOT, Renato } \\
\text { Vairo. Taxonomia } \\
\text { de Bloom: revisão } \\
\text { teórica e } \\
\text { apresentação das } \\
\text { adequações do } \\
\text { instrumento para } \\
\text { definição de } \\
\text { objetivos } \\
\text { instrucionais. } \\
\text { Gestão\& } \\
\text { Produção, São } \\
\text { Carlos, v. 17, n 2, p. } \\
\text { 421-431. 2010. } \\
\text { GATTI, Bernadete } \\
\text { A. O professor e a } \\
\text { Avaliação em Sala } \\
\text { de Aula. Estudos } \\
\text { em Avaliação } \\
\text { educacional. São } \\
\text { Paulo, n. 27, p. 97- } \\
\text { 114, jan-jun, 2003. }\end{array}$ \\
\hline
\end{tabular}




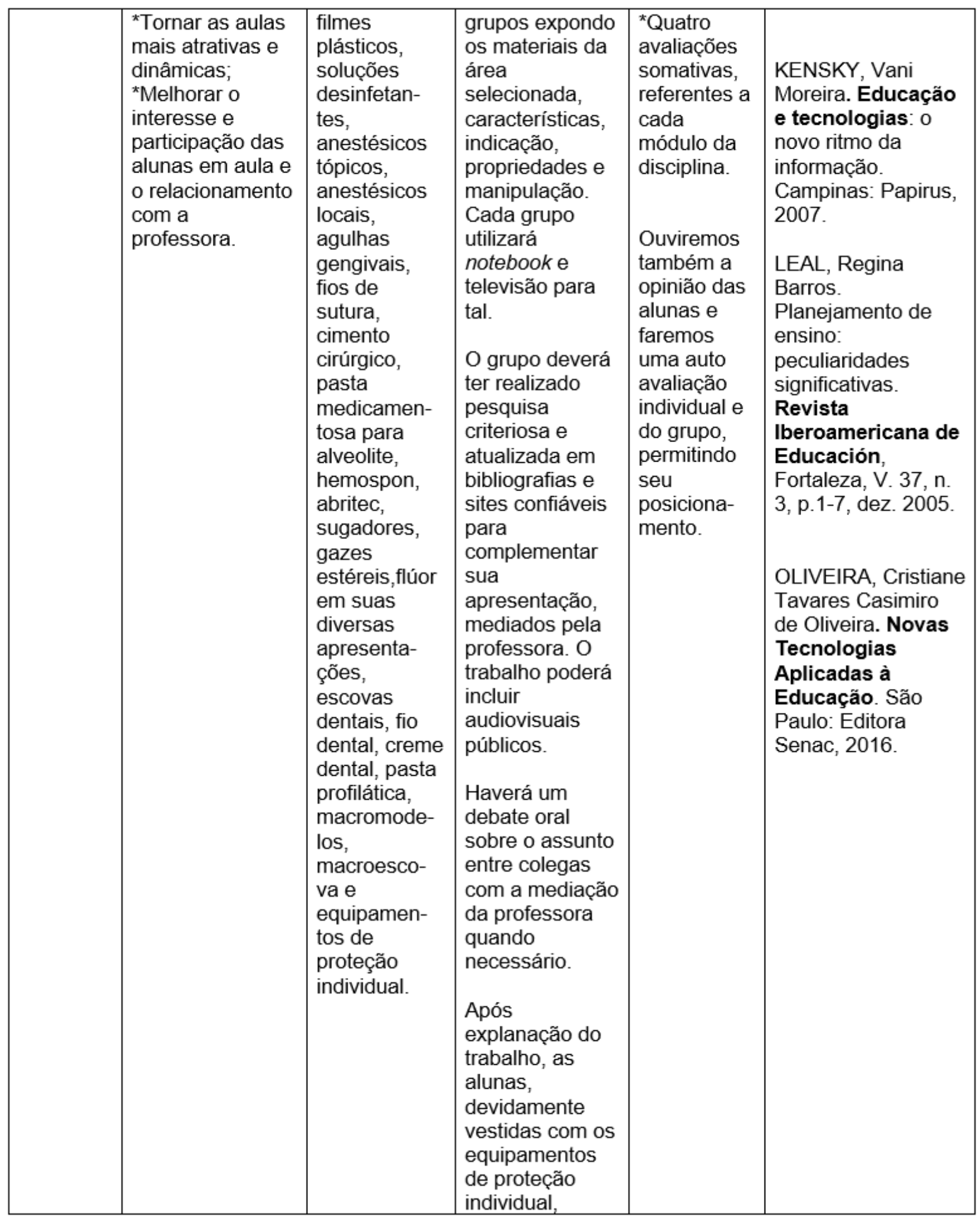




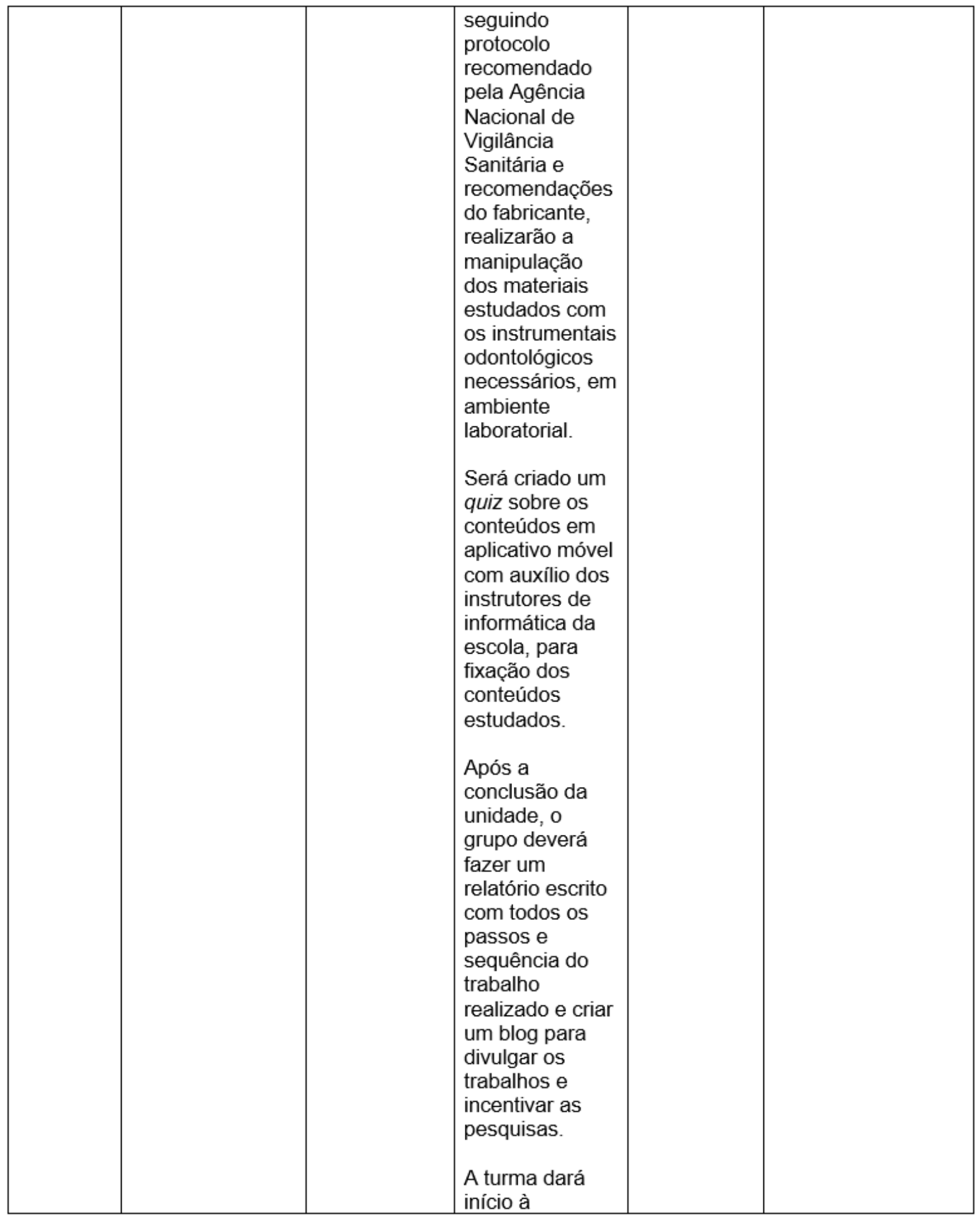




\begin{tabular}{|c|c|c|c|}
\hline & & & $\begin{array}{l}\text { construção de } \\
\text { um portfólio } \\
\text { sobre materiais } \\
\text { dentários e a } \\
\text { cada } \\
\text { apresentação } \\
\text { irão o } \\
\text { complementan- } \\
\text { do até a } \\
\text { conclusão da } \\
\text { disciplina. } \\
\\
\text { Também } \\
\text { criaremos um } \\
\text { grupo com um } \\
\text { aplicativo móvel } \\
\text { para telefone } \\
\text { celular com o } \\
\text { objetivo de } \\
\text { sanar dúvidas, } \\
\text { compartilhar } \\
\text { informações e } \\
\text { mantê-las } \\
\text { atualizadas } \\
\text { dando } \\
\text { continuidade ao } \\
\text { estudo. } \\
\text { Outras } \\
\text { sugestões de } \\
\text { atividades } \\
\text { utilizando TICs } \\
\text { poderão partir } \\
\text { das alunas e } \\
\text { serem utilizadas } \\
\text { em momento } \\
\text { oportuno. }\end{array}$ \\
\hline $\begin{array}{l}\text { II- } \\
\text { Materiais } \\
\text { de } \\
\text { Prótese } \\
\text { Dentária } \\
\text { e }\end{array}$ & $\begin{array}{l}\text { "Identificar, } \\
\text { debater e } \\
\text { manipular } \\
\text { adequadamente } \\
\text { o uso dos } \\
\text { materiais } \\
\end{array}$ & $\begin{array}{l}\text { Característi- } \\
\text { cas, } \\
\text { proprieda- } \\
\text { des, } \\
\text { indicação e }\end{array}$ & \\
\hline
\end{tabular}




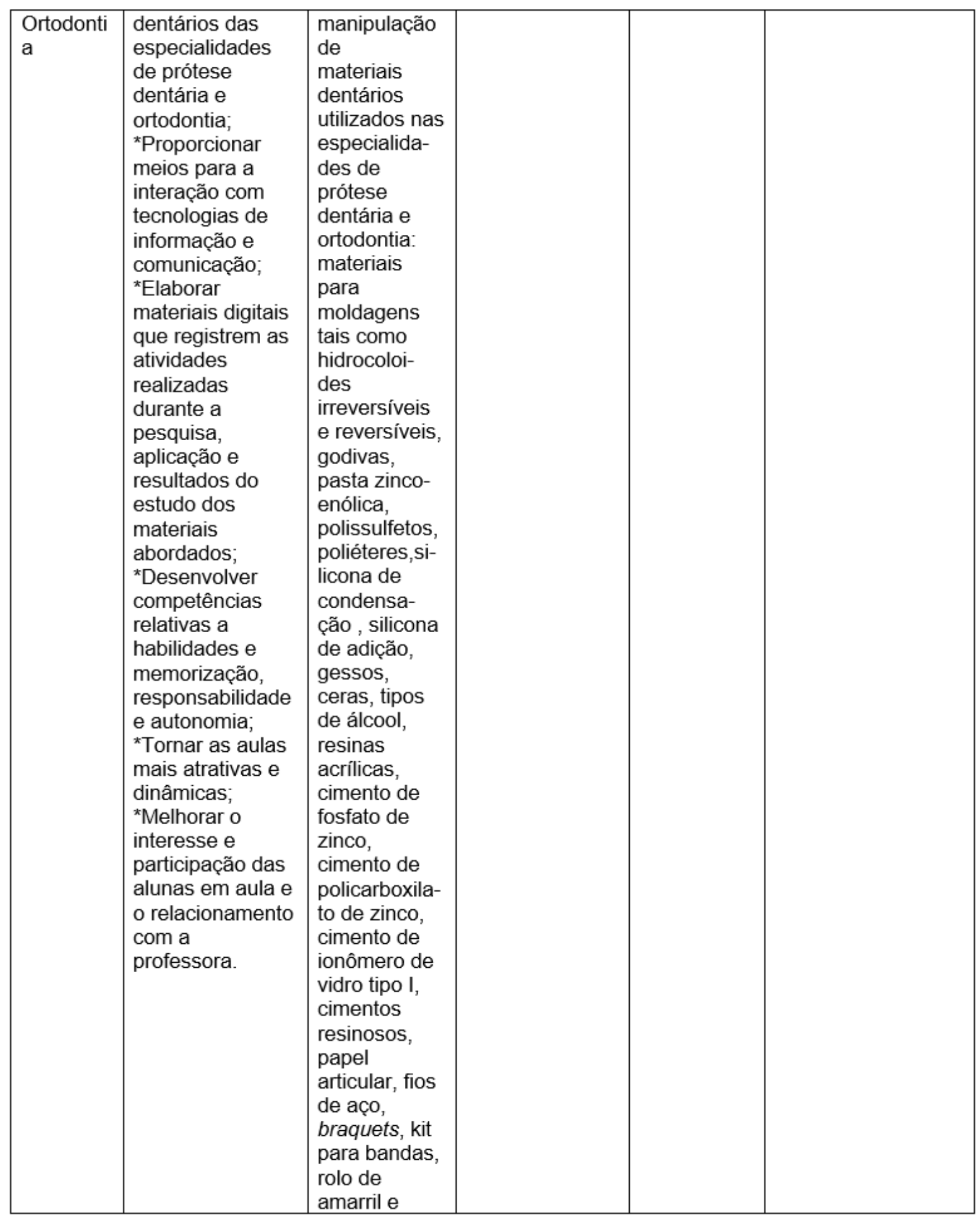




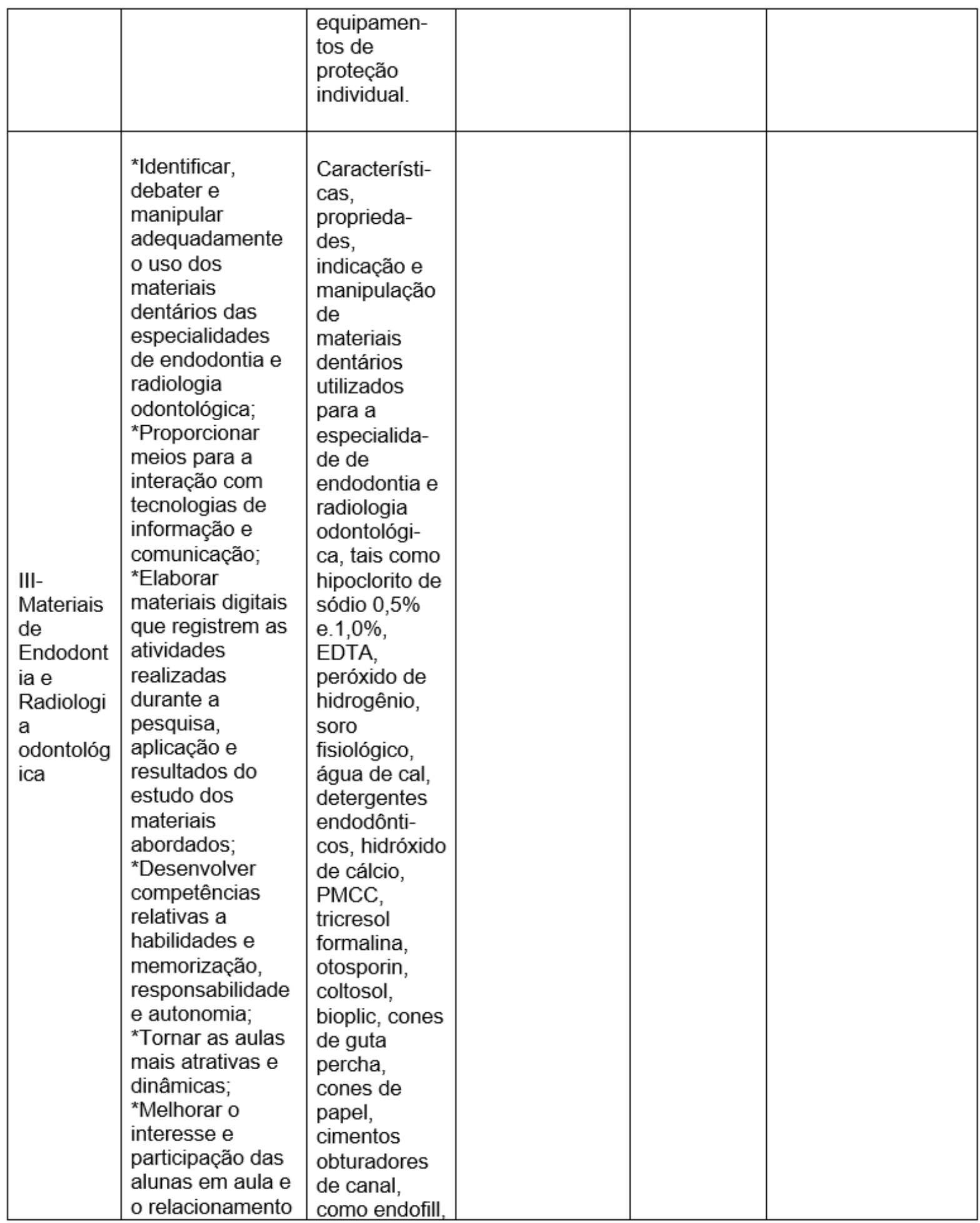




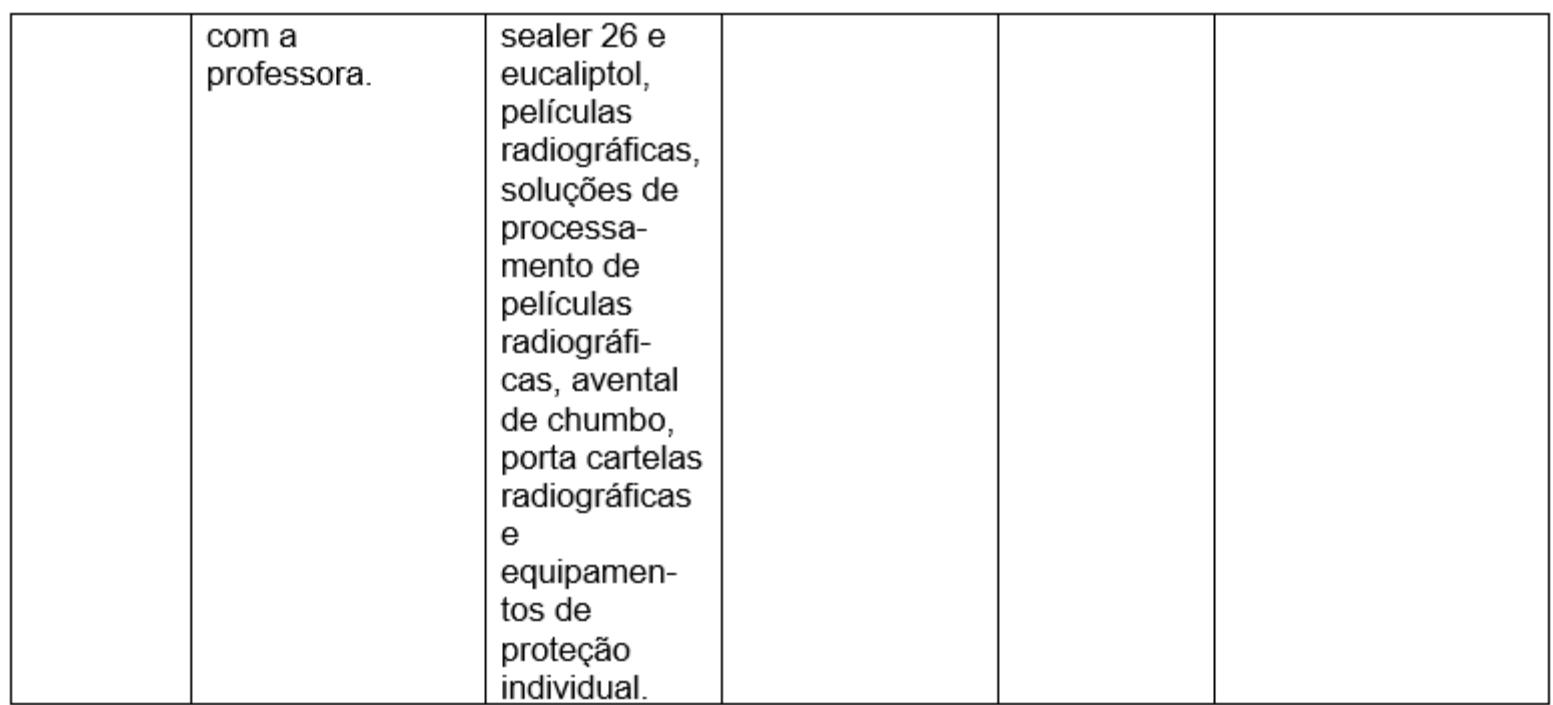

\subsubsection{QUADRO RUBRICA DE AVALIAÇÃO}

A cada unidade desenvolvida utilizaremos esse quadro de rubrica, com os critérios e níveis desdobrados. Cada aluna será avaliada de acordo com seu desempenho e receberá um feedback no final de cada unidade, já que o que varia nessa disciplina são apenas os materiais odontológicos que deverão ser estudados em cada especialidade.

\begin{tabular}{|c|c|c|c|}
\hline DESCRIÇÃO & INSATISFATÓRIO & $\begin{array}{l}\text { PARCIALMENTE } \\
\text { SATISFATÓRIO }\end{array}$ & SATISFATÓRIO \\
\hline 1- Pontualidade & Não compareceu & $\begin{array}{l}\text { Compareceu com } \\
\text { atraso }\end{array}$ & $\begin{array}{l}\text { Compareceu no } \\
\text { horário marcado }\end{array}$ \\
\hline 2- Assiduidade & $\begin{array}{lr}\text { Não compareceu } \\
\text { em nenhuma } \\
\text { atividade }\end{array}$ & $\begin{array}{l}\text { Compareceu em } \\
\text { algumas } \\
\text { atividades }\end{array}$ & $\begin{array}{ll}\text { Compareceu } & \text { em } \\
\text { todas } & \text { as } \\
\text { atividades } & \end{array}$ \\
\hline $\begin{array}{l}\text { 3- Interesse nas } \\
\text { atividades }\end{array}$ & $\begin{array}{l}\text { Não apresentou } \\
\text { nenhum interesse }\end{array}$ & $\begin{array}{l}\text { Apresenta } \\
\text { interesse } \\
\text { vezes }\end{array}$ & $\begin{array}{l}\text { Apresenta } \\
\text { interesse } \\
\text { todas } \\
\text { atividades }\end{array}$ \\
\hline $\begin{array}{l}\text { 4- Organização do } \\
\text { material }\end{array}$ & Sem organização & $\begin{array}{l}\text { Organiza alguns } \\
\text { materiais }\end{array}$ & $\begin{array}{l}\text { Todo o material } \\
\text { organizado }\end{array}$ \\
\hline
\end{tabular}




\begin{tabular}{|c|c|c|c|}
\hline $\begin{array}{l}\text { 5- Participação } \\
\text { nas atividades }\end{array}$ & $\begin{array}{l}\text { Não participa de } \\
\text { nenhuma atividade }\end{array}$ & $\begin{array}{l}\text { Participa de } \\
\text { algumas } \\
\text { atividades }\end{array}$ & $\begin{array}{l}\text { Participa de todas } \\
\text { as atividades }\end{array}$ \\
\hline $\begin{array}{l}\text { 6- Criatividade na } \\
\text { produção do } \\
\text { material }\end{array}$ & Sem criatividade & $\begin{array}{l}\text { É criativo por } \\
\text { vezes }\end{array}$ & Muito criativo \\
\hline $\begin{array}{l}\text { 7- Interação com } \\
\text { tecnologias }\end{array}$ & Não sabe utilizar & $\begin{array}{ll}\text { Utiliza } & \text { com } \\
\text { dificuldade } & \end{array}$ & $\begin{array}{ll}\text { Utiliza } & \text { com } \\
\text { destreza } & \end{array}$ \\
\hline $\begin{array}{l}\text { 8- Colaboração } \\
\text { com a equipe }\end{array}$ & Não colabora & Colabora às vezes & Colabora sempre \\
\hline 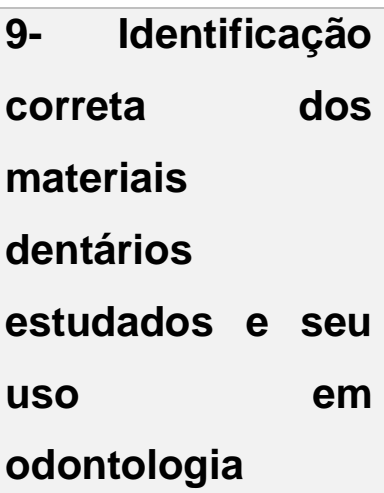 & Não identifica & $\begin{array}{l}\text { Identifica } \\
\text { parcialmente }\end{array}$ & $\begin{array}{l}\text { Identifica } \\
\text { completamente }\end{array}$ \\
\hline $\begin{array}{l}10 \text { - Debate do } \\
\text { assunto com as } \\
\text { colegas }\end{array}$ & Não participa & Participa pouco & Muita participação \\
\hline $\begin{array}{l}\text { 11- Manipulação } \\
\text { adequada do } \\
\text { material dentário } \\
\text { quando solicitado }\end{array}$ & $\begin{array}{l}\text { Não manipula } \\
\text { adequadamente }\end{array}$ & $\begin{array}{l}\text { Manipula com } \\
\text { dificuldade }\end{array}$ & $\begin{array}{ll}\text { Manipula } & \text { com } \\
\text { destreza } & \end{array}$ \\
\hline $\begin{array}{l}\text { 12- Utilização do } \\
\text { vestuário e EPIs } \\
\text { necessários para } \\
\text { manipulação dos } \\
\text { materiais } \\
\text { odontológicos }\end{array}$ & Não utiliza & $\begin{array}{l}\text { Utiliza } \\
\text { parcialmente }\end{array}$ & Utiliza totalmente \\
\hline
\end{tabular}




\section{CONSIDERAÇÕES FINAIS}

Ao final do trabalho, evidenciamos a necessidade de inovarmos as estratégias educacionais utilizadas no ensino técnico, mais especificamente no curso de formação de Auxiliares de Saúde Bucal, disciplina de Materiais Dentários, extrapolando os métodos tradicionais de ensino e intensificando o processo ensino-aprendizagem com a utilização de metodologias ativas, no caso, as tecnologias de informação e comunicação.

Exploramos o tema estudado por autores renomados e verificamos ser essa uma competência a ser desenvolvida pelo professor e pelos alunos que serão preparados para as exigências do atual mercado de trabalho e para convívio social em geral.

O atual perfil do nosso aluno permite o desenvolvimento das estratégias propostas e consecução dos objetivos, devido a sua faixa etária e larga utilização que fazem naturalmente das tecnologias, inclusive em sala de aula. A inclusão das TICs no currículo tornará as aulas ativas, atrativas e interessantes.

\section{REFERÊNCIAS}

ADMINISTRAÇÃO REGIONAL DO SENAC NO ESTADO DE SÃO PAULO. Guia Trabalho de Conclusão de Curso. São Paulo: Editora Senac, 2017.

COSTA, Maria Salete da; ENDO, Whaner. Trabalho de Conclusão de Curso Docência no Ensino Técnico. Editora Senac, 2017.

KENSKY, Vani Moreira. Educação e tecnologias: o novo ritmo da informação. Campinas: Papirus, 2007.

LEAL, Regina Barros. Planejamento de ensino: peculiaridades significativas. Revista Iberoamericana de Educación, Fortaleza, V. 37, n. 3, p.1-7, dez.

LÉVY, Pierre. Da interconexão caótica à inteligência coletiva. In:_Cibercultura. 2 ed. São Paulo: Editora 34, 1999. p. 167- 169. 
OLIVEIRA, Cristiane Tavares Casimiro de Oliveira. O docente para o século XXI. In: Novas Tecnologias Aplicadas à Educação. São Paulo: Editora Senac, 2016.

PRETTO, Nelson de Lucca. A educação num mundo de comunicação. In: uma escola com/sem futuro: educação e multimídia.8. ed. Campinas: 2005.

REDE DE BIBLIOTECAS DO SENAC DE SÃO PAULO (organizadora). Guia de normalização de monografias, dissertações e teses. São Paulo: Editora Senac, 2014. Papirus, 2013. p. 119- 144.

SALDANHA, Rubem Paulo Torri. Indicadores de um currículo flexível no uso de computadores portáteis. 2009. Dissertação de Mestrado- Programa de PósGraduação em Educação: Currículo, Pontifícia Universidade Católica de São PauloPUC, São Paulo, 2009.

SETTON, Maria da Graça. Considerações finais. In:_ Mídia e educação: São Paulo: Contexto, 2010.

SILVA, Jayson Magno da; SILVA, Maria da Graça Moreira da. A escola e o currículo em tempos de mobilidade e conexão: o uso de computadores portáteis na educação. 3o Congresso Brasileiro de Informática na Educação (CIEB 2014), Workshops (WCBIE 2014), 2014.

Enviado: Maio, 2019.

Aprovado: Outubro, 2019. 